\title{
ERRATUM
}

\section{Hypogonadism in men with erectile dysfunction may be related to a host of chronic illnesses}

\author{
A Guay ${ }^{1}$, AD Seftel $^{2}$ and A Traish ${ }^{3}$ \\ ${ }^{1}$ Department of Endocrinology, Center for Sexual Function, Lahey Clinic Northshore, Peabody, MA, USA; ${ }^{2}$ Department of \\ Urology and Reproductive Biology, Case Western Reserve University, Cleveland, OH, USA and ${ }^{3}$ Departments of \\ Biochemistry and Urology, Boston University School of Medicine, Boston, MA, USA
}

International Journal of Impotence Research (2010) 22, 210; doi:10.1038/ijir.2010.3

Correction to: International Journal of Impotence Research (2010) 22, 9-19; doi: 10.1038/ijir.2009.46

Figure 2 in the print version (http://www.nature. com/ijir/journal/v22/n1/pdf/ijir200946a.pdf) of the above article was inadvertently changed after the paper published correctly online ahead of print publication. We apologize for any confusion.

The correct figure and legend are shown below.

$\begin{array}{cl}\begin{array}{c}\text { Hypertension } \\ \text { Overall } \\ \text { Less than } 40 \\ 40 \text { to } 59 \\ 60 \text { and older }\end{array} \\ \text { Sleep Apnea } & \begin{array}{l}\text { Overall } \\ \text { Less than } 40 \\ 40 \text { to } 59 \\ 60 \text { and older }\end{array} \\ \text { Tobacco Abuse Overall } \\ \text { Less than } 40 \\ 40 \text { to } 59 \\ 60 \text { and older }\end{array}$

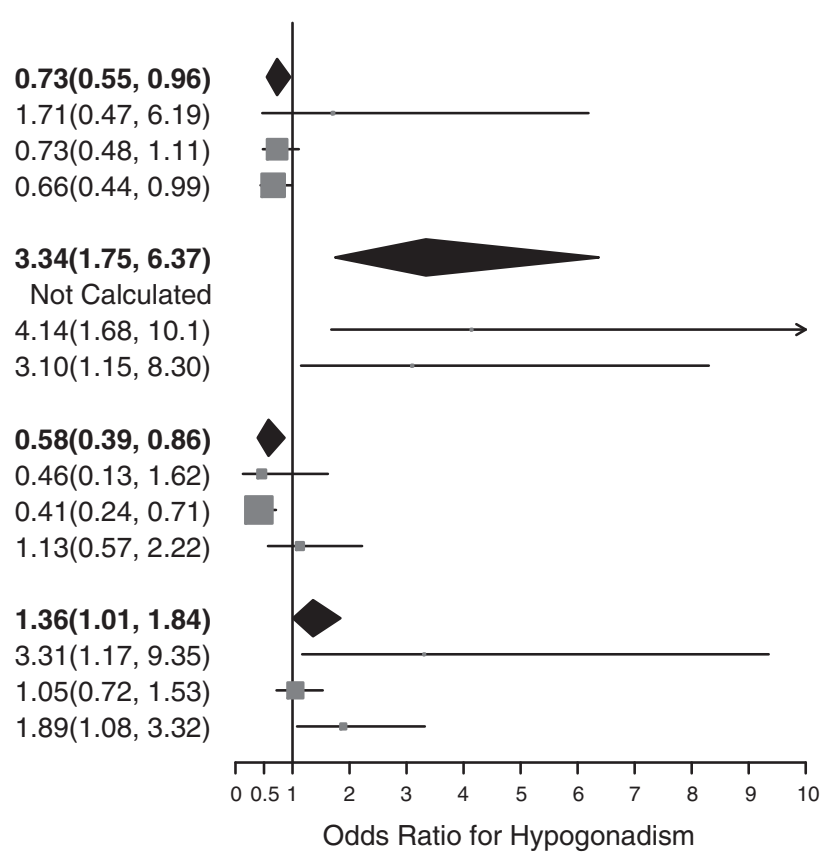

$0.73(0.55,0.96)$

$1.71(0.47,6.19)$

$0.73(0.48,1.11)$

$0.66(0.44,0.99)$

$3.34(1.75,6.37)$

Not Calculated

$4.14(1.68,10.1)$

$3.10(1.15,8.30)$

$\mathbf{0 . 5 8}(0.39,0.86)$

$0.46(0.13,1.62)$

$0.41(0.24,0.71)$

$1.13(0.57,2.22)$

$1.36(1.01,1.84)$

$3.31(1.17,9.35)$

$1.05(0.72,1.53)$

$1.89(1.08,3.32)$

Figure 2 Summary of the strength of associations between hypogonadism and chronic illnesses that showed significance, using Cochran-Mantel-Haenszel estimates stratified by age and represented by Forest plot. 